\section{TRANSGRESIÓN BANAL: DISCURSOS, IDENTIDADES Y ESTEREOTIPOS DE GÉNERO ENTRE LOS AÑOS 70 Y 80}

\author{
Alicia Mira Abad \\ Universidad de Alicante \\ ORCID iD: http://orcid.org/0000-0003-0009-4791 \\ Alicia.mira@ua.es \\ Elena Díaz Silva \\ Universidad de Colonia \\ ORCID iD: http://orcid.org/0000-0003-4581-107X \\ ediazsilva@outlook.com
}

\section{BANAL TRANSGRESSION: DISCOURSES, IDENTITIES AND GENDER STEREOTYPES IN THE SEVENTIES AND EIGHTIES}

Cómo citar este artículo/Citation: Mira Abad, A. y Díaz Silva, E. (2020). Transgresión banal: discursos, identidades y estereotipos de género entre los años 70 y 80. Arbor, 196 (796): a555. https://doi.org/10.3989/arbor.2020.796n2008
Copyright: (c) 2020 CSIC. Este es un artículo de acceso abierto distribuido bajo los términos de la licencia de uso y distribución Creative Commons Reconocimiento 4.0 Internacional (CC BY 4.0).

Recibido: 26 mayo 2018. Aceptado: 23 octubre 2019.

RESUMEN: El objetivo de este trabajo es analizar las diversas manifestaciones de transgresión que tienen su origen en los últimos años de la década de los 70 y en los 80 en España, y su reflejo en los estereotipos de género. Desde las actitudes libertarias, pasando por la superwoman como modelo de mujer emancipada, hasta los nuevos modelos de maternidad intensiva que comienzan a introducirse a finales de los ochenta, la transgresión se ha manifestado de diversas formas durante este periodo en el que las españolas a duras penas lograron superar el modelo tradicional impuesto por el franquismo. En este contexto, la transgresión se manifestó como un fenómeno superficial, inherente al momento sociopolítico y vaciada de un contenido reivindicativo.

PALABRAS CLAVE: Transgresión; banalización; estereotipos de género; maternidad; cómic; feminismo; activismo.
ABSTRACT: The aim of this paper is to explore the different ways transgressive cultural expressions emerged in the late seventies and eighties in Spain, and their impact on gender stereotypes. From libertarian attitudes, the overcoming of superwoman as a model for the emancipated woman, to new methods of parenthood known as attachment parenting introduced in the late eighties, transgression has several manifestations during this period in which Spanish women scrambled to overcome the traditional model imposed by Francoism. In this context, transgression was manifested as a superficial phenomenon inherent to the socio-political moment and devoid of any protest content.

KEYWORDS: Transgression; banality; gender stereotypes; motherhood; comic; feminism; activism. 
En este trabajo nos aproximamos al final de los años 70 y a la década de los 80 a partir de las diversas manifestaciones de la transgresión como "registros de comunicación efímera" (Gómez Alonso, 2013, pp. 199-214), ajenos a una categorización política o cultural, cuyo único punto común fue mostrar la ruptura con un tiempo pasado. No entramos por tanto en el campo de la militancia, sino en un abanico referencial mucho más amplio que incide en la construcción de unos estereotipos de género sujetos a un ideal transformador. Nos interesan desde las actitudes libertarias de finales de los 70, pasando por la construcción de la superwoman de los años 80, emancipada y libre para tomar sus propias decisiones, hasta el relato de una maternidad presentada como una nueva tierra prometida en la que poder aterrizar desde el empoderamiento femenino en los 90. Ya al final de la dictadura aparecen las primeras señales de renovación respecto al rol tradicional de madre y esposa. El movimiento feminista, que comenzaba su reorganización por entonces, cuestionó directamente ese ideal de feminidad, y especialmente la maternidad, como destino principal o esencia femenina. La anticoncepción y el aborto, la recuperación del control sobre el cuerpo y la sexualidad o el cuestionamiento de la familia tradicional se convirtieron en objeto de reivindicación permanente (Mira Abad y Moreno Seco, 2004, p. 330). Tras la muerte de Franco, los últimos coletazos del feminismo de segunda ola llegaban a España sin que sus aguas reivindicativas impregnaran el horizonte vital de muchas mujeres. La puerta del cambio les ofreció una imagen de la transgresión muy superficial, construida desde el cine, la música, la publicidad, las revistas femeninas y la llamada contracultura, considerada ya en esos momentos como el "colorín del underground", manifiesto en "el comix, las flores en el pelo, el neonaturismo y la mitología del puerro"; un "invento de los snobs americanizantes", tan "irrelevante, ficticio y nimio que ni resiste ni merece discusión ninguna" (véase Savater, "Sobre la contracultura, la incultura y todo lo que lleva a la sepultura").

La mayor parte de las referencias aportadas representan una transgresión percibida como inherente al momento sociopolítico, de manera que podía ser vaciada de contenidos reivindicativos. Resulta paradójico que un proceso impulsado por la destrucción de los viejos estereotipos y convenciones se redujera en muchos casos a una mera simulación de rebeldía o irreverencia sin rumbo. Los "modernos, progres, feministas, pacifistas y grupos periféricos" (Lladó, 2001, p. 27) protagonizaron una "rebelión" que sobrepasaría los límites de un cambio generacional marcado por una estética o unos hábitos radicalmente distintos a los de sus progenitores y por un discurso transgresor muy heterogéneo. Su argamasa referencial era la contestación al poder establecido y la superación de un pasado forjado bajo la oscuridad franquista. El hecho de que las mujeres adquirieran protagonismo público en este contexto ya se consideraba un signo de transgresión.

Analizamos las diversas narrativas de la transgresión desde sus manifestaciones más explícitas, encarnadas por el discurso libertario o el autodenominado underground y su ofensiva contracultural, hasta su percepción como proceso natural o derivado del cambio sociopolítico en España. La idea subyacente en el discurso transgresor no siempre era alterar o desestabilizar el mainstream volviendo del revés los estereotipos vigentes. Además, tras el franquismo, emerge una transgresión "constatativa" (Austin, 1991), que no apelaba a la subversión porque se asumió como un proceso natural, inherente al propio relevo vital que encarnan las mujeres jóvenes, situadas en las antípodas de los patrones convencionales que representaron sus madres y abuelas. De ahí, la necesidad de prestar atención a las expresiones consideradas contraculturales, evidentes en el mundo del cómic o en la música. Pero también, a otras manifestaciones perfectamente identificables en las llamadas publicaciones femeninas que, como señala Anne-Marie Dardigna (1978), lejos de dar la palabra a las mujeres o traducir sus preocupaciones, las suprimen al eliminar cualquier elemento dialéctico, introduciéndolas en una especie de afasia bajo la apariencia de una transgresión controlada, canalizada, realizada en el día a día a través de imágenes de una feminidad triunfadora, encastrada en un esquema teleológico (p. 102).

El concepto de transgresión y sus diversas interpretaciones ha sido analizado a partir de dos ejes bien definidos: En el primero, abordamos lo que nosotras consideramos como transgresión banal, un concepto que, como veremos posteriormente, está relacionado con la construcción de los nuevos estereotipos transgresores cuyo impacto nos interesa especialmente desde la perspectiva del universo libertario o del cómic adulto. En el segundo, nos aproximamos a la maternidad, como proceso sobre el que se ha construido la idea de feminidad desde el siglo XIX, y los estereotipos derivados de su exposición a la transgresión de los años 70 y 80 , a partir de algunas de las figuras más relevantes del cómic feminista y de las publicaciones familiares. Un enfoque que pone de manifiesto las contradicciones de unos años que ya por sí mismos se han convertido en un estereotipo del cambio y la libertad. 


\section{LA TRANSGRESIÓN BANAL Y SU REFLEJO EN LA CONSTRUCCIÓN DE LOS ESTEREOTIPOS DE GÉNERO EN LA ESPAÑA DE LOS AÑOS 70 Y 80}

Estudiamos un periodo en el que la idea de cambio impregna la política, la sociedad y la cultura a través de manifestaciones vacuas que podían adquirir inmediata legitimidad por el mero hecho de que contrastaban "con el gris oscuro y raído de la dictadura". El resultado no fue una transformación "revolucionaria" sino "de superficie" (Pardo, 2006, p. 1), visible en un relato del "deber ser abstracto" cuya materialidad derivaba de las palabras, los gestos y las imágenes. La revista libertaria y contracultural Ajoblanco recoge a la perfección ese espíritu. Sus redactores se declaraban herederos del 68 y representantes de quienes no habían "vivido más experiencia que la transición". La cultura como "plataforma creativa" que facilita "la apertura al diálogo sin cortapisas" no renunciaba al "ocio y diversión", el "cachondeo y compromiso", la "imaginación y fantasía, pero jamás corrupción". Ambigüedad e idealismo en una visión de "lo social" que integra el "talento, la ética, la sensibilidad, el agua, el inconformismo, la política otra, la civilidad, las asociaciones de las ciudades, las artes, la educación, el mestizaje, el politeísmo, la cultura, los equipos, las redes, la poligamia, la transgresión..." (Ribas, Puig y Esteban, 2004, p. 5).

No estamos ante un fenómeno exclusivamente español. La rotura de los viejos esquemas teleológicos de la modernidad, la subversión de la universalidad y de cualquier signo de historicidad se hace visible en un mundo globalizado. La estética de la resistencia se generaliza a partir de una "microrrevolución de la banalidad o transpolítica del deseo" (Wolen, 2006). La pura apariencia es la transgresión; no es un engaño: es el verdadero objetivo. Detrás de la deslegitimación del poder establecido o de cualquier principio de dominación no existe ninguna aspiración hegemónica. Se trataría de la "liquidación de todos los referentes" y la "generación simulada de diferencias" (Baudrillard, 1984), a partir de múltiples propuestas que van desde las reivindicaciones libertarias a las estéticas más perturbadoras y a la torsión de códigos e identidades más llamativos (Nelly, 1989, p. 17).

En España estos procesos se ven condicionados por un pasado que lastraba inevitablemente la apertura hacia nuevas expectativas. Las jóvenes de la época miraban por primera vez más allá de la maternidad y el matrimonio. Junto al progresivo acceso de las mujeres a la educación superior, nos encontramos con que ya hacia 1970 comenzaba a registrarse un au- mento de las tasas de actividad femenina que pasaría del 22\% en 1964 al 33\% en 1990 (Alberdi, 1996, p. 46; Garrido, 1992). El salto es enorme, especialmente para las mujeres jóvenes con estudios medios y superiores. Son mujeres que, a diferencia de sus madres, conservan la actividad laboral en periodos sucesivos. Sus progenitoras abandonaban la actividad profesional tras contraer matrimonio. En cambio, sus hijas podían compatibilizar matrimonio, hogar, trabajo extradoméstico y maternidad. Es una transformación generacional profunda, acompañada por la "negación" de los modelos de feminidad y masculinidad vinculados a la losa de la dictadura. Pero desde una perspectiva cultural, la forma de canalizar este cambio de paradigma no fue homogénea. Muchas de estas jóvenes no estaban "entrenadas" en la lucha política, de manera que su interpretación de la transgresión se manifestaba en elementos tan efímeros como la apariencia y la ambigüedad (Baudrillard, 1984, p. 12). La "absolutización de la diferencia" constituía una fórmula de derribo de "convenciones y conveniencias" (Bourdieu, 1988, pp. 44-45) que no derivaba de la militancia sino de una especie de actitud vital de rechazo hacia lo establecido. El propio cuerpo adquiría protagonismo en la expresión de actitudes de resistencia (Benavides, 2016) que podríamos calificar de somáticas porque las formas de oposición al llamado mainstream no estaban construidas desde parámetros racionales o funcionales. El testimonio de la cantante Ana Curra, que se autocalifica como una transgresora frente a los "perdedores", resulta sumamente esclarecedor en este sentido:

Íbamos a los pueblos de España y nos llamaban brujas, putas y zorras. En algún sitio concreto tuvo que venir la Guardia Civil porque estuvieron a punto de tirar los camerinos porque nos querían violar [...]. No obstante, yo, como mujer, me divertía mucho. Era muy joven, estaba descubriendo el mundo y me provocaba mucha diversión ir por la calle viendo cómo te miraban, no sabías si como una zorra puta o escandalizados. Había ese morbo de epatar por parte nuestra, al menos por parte mía, a toda esa gente mayor que pretende que porque eres mujer le debes algo. La verdad es que este tipo de cosas las he intuido cuando las he tenido enfrente, pero no me han causado ningún shock en mi vida, siempre me he sentido por encima de estas historias. No he tenido que luchar en el mundo de las feministas porque consideraba que lo tenía ya superado (véase Ana Curra: "Hubo dos Movidas: la light que se ha vendido, y la de los perdedores y transgresores") $)^{1}$. 
Pero no todas las manifestaciones tenían por objeto escandalizar. Las revistas femeninas de la época también proponían su propio modelo transgresor de mujer (Muñoz Ruiz, 2002), aunque solo fuera un mero revoco del eterno femenino y sus atributos tradicionales (Domínguez Juan, 1988). Estas publicaciones fagocitan la idea de transgresión. La domestican a través de la imagen de una mujer triunfadora, confeccionada a partir de la superposición de nuevos roles sobre los viejos. Aunque aparentemente se supera el modelo de la mujer complementaria, muestran una feminidad sexuada, centrada en la seducción y en una disponibilidad sexual que es interpretada como un signo de libertad (Jareño, 2016, pp. 179-198). En estas revistas el nosotras no tiene por objeto crear una identidad; justamente es lo contrario: se individualiza con fines publicitarios. Los antiguos roles son fácilmente identificables en este texto de la revista Cómplice publicado en septiembre de 1985:

A ti, mujer activa, que sabes administrar tu dinero; a ti que te interesas por los temas actuales y haces que avancen las ideas nuevas; a ti que tomas decisiones autónomas y eres capaz de lograr que funcionen las cosas [...]; triunfar en el trabajo y pintar algo en el mundo; ser feliz con un hombre y tener hijos magníficos; vivir en una casa acogedora que los amigos frecuentan [...] tener una imagen súper y un tipo extra. Ser ni más ni menos que una mujer de ahora, es decir iun superhombre! (Gallego Ayala, 1990, p. 93).

\section{DOS MIRADAS DISTINTAS: DE LA TRANSGRESIÓN LIBERTARIA DE AJOBLANCO EN LOS ÚLTIMOS 70 A LA TRANSGRESIÓN DE LOS MODELOS DE FEMINIDAD EN EL CÓMIC DE LOS 80}

Como hemos señalado anteriormente, el concepto de transgresión y su impacto en los modelos de género tradicionales nos permite abarcar visiones muy distintas en torno al imaginario del cambio y la transformación social. La revista libertaria Ajoblanco es una de las manifestaciones más claras de ese impacto. Su primer número vio la luz en 1974. A finales de esa década muestra la efervescencia de una juventud que quería romper con todos los símbolos tradicionales de género, como el matrimonio, la maternidad o la educación, pero que en ocasiones adolecía de escasa profundidad "revolucionaria". La información que nos ofrece la revista sobre las Primeras Jornadas Libertarias Internacionales organizadas en Barcelona por la CNT en julio de 1977, nos aproxima a las contradicciones en torno a la transformación de esos modelos y la búsqueda de referentes sobre los que anclar el ideario revolucionario. Una muestra es la entrevista a
Daniel Cohn-Bendit, uno de los líderes de mayo del 68 en Nanterre, conocido en esa época como Dany el rojo y autodenominado en 1999 como "libertario liberal" (Hernández Velasco, 2017, 7 de mayo)². Con motivo de su participación en las Jornadas, él mismo definía la experiencia revolucionaria del 68 como "inigualable, pero con los pies de barro", con unos ideales de "transformación profunda y radical de la sociedad", aunque distanciándose de la militancia izquierdista tradicional concebida como "una carrera por ver quién llegaba antes o a quién le ponían el título de revolucionario". Cuando se le pregunta en qué puesto dejaba a las mujeres, la respuesta resulta concluyente:

Desde luego somos culpables de que se nos acusara de machistas, queríamos cambiar las cosas, pero a nuestras compañeras sólo les dejábamos servir el café y ayudarnos a pasar los textos "revolucionarios" a máquina. Yo apoyo la causa feminista de la mujer, en esto he cambiado mucho, como también apoyo las luchas de los marginados y los homosexuales, pero creo que las mujeres deben luchar ellas solas, todas juntas ${ }^{3}$.

Karmele Marchante, una de las redactoras en esos años, utiliza la expresión machismo ácrata para describir la actitud de unos anarquistas que en esas mismas Jornadas celebradas en el parque Güell hicieron gala de su "protagonismo verbal" y su "insistente y famosa capacidad para la especulación abstracta" para acaparar toda la atención. Las feministas allí presentes decidieron reunirse en otra parte para hablar de "esas cosas estúpidas que nos preocupan: familia, reproducción, derecho a nuestro cuerpo, defensa frente a la violación y otras violencias...". La reacción de los varones "cargados de símbolos anarquistas" no se hizo esperar. Acompañados por Mujeres Libres, las "compañeras de anarquistas", que corrían en "ayuda de sus hombres", las insultaron Ilamándolas "reaccionarias, fascistas, lesbianas, stalinistas y machistas" ${ }^{\text {. El recha- }}$ zo a las formaciones políticas tradicionales se puso de relieve en otro artículo titulado "Sostenes y violetas a Teresa Pàmies, de las radicales con amor" (marzo 1977), en el que la periodista arremete contra la histórica dirigente comunista con estas palabras: "aquello no es una mujer. Es "algo", me repugnaría tener que llamarla hombre". Marchante critica su identificación total con la "cultura dominante" y declara un "RIP para Teresa Pàmies y su pretendido feminismo. Oportunismo, sí. Las feministas no queremos ser engañadas".

Una de las fórmulas que cuestionaba directamente, al menos en teoría, los estereotipos tradicionales era el ideal comunal, que materializaba la liberación sexual y la definitiva disolución de roles. Sin embargo, 
los testimonios apuntan en otra dirección y vinculan a la comuna con su propio estereotipo. Como señala Melville (1980), cada comuna "es como un test de Rorschach [...]. Los visitantes esperan encontrarse con el amor libre, cuerpos desnudos, hippies ociosos y un poco sucios [...], pero los curiosos no captan nada de lo que en realidad está sucediendo" (p. 143). Pepe Ribas, fundador de Ajoblanco, e impulsor él mismo de una comuna, señala que en realidad "tampoco fuimos tan libres". La moral franquista y el catolicismo conservador habían establecido un divorcio total entre cuerpo y alma difícil de corregir en un santiamén" (Ribas, 2011, p. 237). Por un lado, estaban las agrupaciones vinculadas a la gauche divine, en las que podías encontrar "mujeres burguesas y extravagantes, bastantes modernas, que iban de poupées y mantenían vínculos editoriales con Lumen". Pero las comunas también fueron fórmulas de convivencia alternativas para muchos jóvenes que buscaban escapar de la opresión familiar. Ribas señala que la "superación de la pareja" constituía un elemento clave porque es "siempre un centro de poder". Además, se mezclaba todo: "la alternativa con la mera huida, la reacción salvaje de romper con el pasado, familia incluida, autoestimulación sexual y pecados, con la bonita idea del campito, la comuna o el piso que todo nos lo va a solucionar, porque entre sus paredes nos haremos todos muy lilis» (Ribas, 1980). Los anuncios en el Ajoblanco de aquellos años muestran esta diversidad: "gente cachonda dispuesta a formar una comuna rural en Galicia", una "comuna en formación" para dos chicas, o un piso para seis personas que permita la "revoluçao", momento en que "seréis ampliamente recompensados a polvos". También se comenta la evolución de algunas de estas experiencias y su fracaso, que en el caso de una comuna madrileña estuvo motivado por problemas relacionados con las parejas porque en realidad "las comunas no son ningún cuento de hadas, son lugares donde todas las contradicciones estallan muy intensamente" (véase Cuadernos comuneros. Ajoblanco, 24, julio 1977; Cloaca. Ajoblanco, 25, septiembre 1977).

Pero es en la sección Cloaca donde la banalización del horizonte transgresor y su impacto en los estereotipos de género se hace más evidente. En algunos momentos se convierte en un tablón de anuncios de contactos envueltos en el halo de la liberación sexual: una "tía liberada de 25 años", "disminuida", reivindica su derecho a "vivir, amar y gozar". Un chico anuncia sus próximas vacaciones que quiere aprovechar para "recapacitar y pensar la manera de sacudirme el yugo que me aprieta. A ver si hay un par de tías o una sola que quiera venir a gastos pagados al piso que pienso arrendar. Prometo cerveza, sardinas, boquerones, pimientos fritos [...] y amor sin límites". O también el anuncio de un "viejo militante de 56 años, obrero manual", que regresa a España "desmoralizado, carcomido por sus propias contradicciones internas, pero libre de todo prejuicio burgués" que desearía relacionarse "con revolucionarias". En otro ejemplo se argumenta el atractivo de una fiesta con "chorvas" y "algún tío de lo más excitante" que se celebra en la noche de Santo Tomás, en la que se prometen "rebeliones estudiantiles semejantes a las de mayo de 1968" con el acicate de un jeep permanente "de grises en la puerta" (véase Cuadernos comuneros. Ajoblanco, 24, julio 1977; Cloaca, Ajoblanco, 18, enero 1977; Cloaca. Ajoblanco, 25 , septiembre 1977).

Si de los personajes de carne y hueso saltamos al universo del cómic, encontramos que esa misma idea de liberación sexual se asume como la transformación definitiva de los modelos de género. Ya en los 60 aparecen figuras de heroínas como Mary Noticias. Amor, misterio, aventura, con un guion muy lineal y una trama inocente, que no pretendía enfrentarse a la censura, pero con una protagonista independiente y aventurera alejada de los cánones vigentes (Acedo y Barbará, 2010). Pero es sobre todo en los 80 cuando las mujeres se convierten en protagonistas, no por intereses comerciales, como hizo Marvel al considerarlas como potenciales lectoras, sino como un signo de subversión. Encontramos los tópicos del underground: sexo, violencia y drogas, que paradójicamente rechazaban esa misma realidad. Al mismo tiempo se va diluyendo la aureola contracultural y subversiva al desaparecer la censura y confluir con la cultura oficial (Lladó, 2001, p.41). Historias como María Lanuit, de Alfredo Pons, nos ofrecen la imagen de una "bailarina de un mediocre cabaret de las Ramblas" en la noche barcelonesa, y la vida en los bajos fondos, cuyo signo transgresor es una sexualidad sin límites ni tapujos (Pons, 1984), que en realidad se reduce a un modelo de mujer cuyo poder reside exclusivamente en la desinhibición sexual. El mismo autor publica un año más tarde y en la misma línea Internas, la historia de "un respetable internado femenino" en el que sus "jovencísimas alumnas" se masturban, se drogan, seducen a sus profesores, se prostituyen "por diversión o mantienen entre ellas relaciones lésbicas", en "una obra, que de existir aún en nuestros días la Santa Inquisición, sería condenada, sin duda alguna, a las purificadoras llamas de sus hogueras" (Pons, Guerrero y Galiano, 1985). Cleopatra es una heroína distinta. Su autor, Mique Beltrán, buscaba una protagonista que no tuviera "un papel meramente ornamental: o eran las 
novias del héroe a quien había que rescatar o tenían un componente puramente erótico, así que pensé en una protagonista guapa y simpática, que no renunciara a su feminidad, pero que asumiera los roles que hasta entonces estaban dirigidos a los hombres, como el liderazgo, la acción, las peleas, y las persecuciones" (véase “Entrevista a Mique Beltrán", 12 de noviembre 2015). Se muestra como una mujer libre en su trabajo y en las relaciones con los hombres (Beltrán, 1987). La protagonista de Zora y los Hibernautas es pacifista, está embarazada e interviene en una trama en la que se invierten los esquemas tradicionales de los protagonistas. También en Ghita de Alizarr, publicada en la revista 1984, la protagonista es una antigua prostituta, alta y rubia, que enfundada en un provocador bikini se convierte en la heroína de la historia (Lladó, 2001, p.75).

\section{MATERNIDAD Y TRANSGRESIÓN: DE LA SUPERWO- MAN A LA CRIANZA CON APEGO}

La incorporación de las mujeres al mercado laboral a partir de los 70 no fue acompañada de un cambio de mentalidad en los varones, que generalmente continuaron sin asumir las tareas derivadas de la paternidad o las labores domésticas. Estos "temas" seguían siendo considerados inherentes a la esencia femenina. Surge así el mito de la superwoman, construido como una transgresión "constatada" frente a los valores de referencia y pautas de conducta de sus progenitoras, representada como una mujer independiente, pero que carga con todas las responsabilidades familiares. El origen del estereotipo, vinculado al cómic y al antagonismo que se establece con el héroe masculino (superman), resulta un modelo irrealizable por la imposibilidad de conjugar la nueva cultura de masas y el mantenimiento de los valores de la familia tradicional (Romero, 2017, p. 3). Es una imagen que busca el empoderamiento femenino a través de una retórica feminista bajo la que subyace una desigualdad encubierta que utiliza la coartada de la libre elección (de Miguel, 2015) y que muy pronto muestra señales de agotamiento tal y como lo expuso en su obra una periodista francesa, célebre por su trabajo como columnista en la revista Elle (Fitoussi, 1989).

La aparición de este modelo coincide con un cambio en las pautas de maternidad. Desde 1970 las tasas de fecundidad sufren un claro descenso en toda Europa, y desde 1980 en España. Además, se observa un descenso de la nupcialidad y un ascenso en la edad del matrimonio (Alberdi, 1996, pp. 51-57). El trabajo y la difícil compatibilidad entre vida familiar y laboral explican, en parte, el constante descenso de la natalidad. La imposición de la doble jornada laboral condiciona la vida de estas mujeres nacidas en el franquismo (Romo Parra, 2001, pp. 55-81) y formadas en la democracia, inmersas en una dinámica económica globalizada que prima la competitividad del mercado y la desigualdad social (Shipman y Kay, 2009) y que determina su evolución vital, tanto en su faceta profesional como familiar.

El cómic, la viñeta y el humor gráfico actuaron en esos años como plataforma crítica ante los modelos tradicionales de feminidad y maternidad. A diferencia del cómix, las ilustradoras e historietistas del cómic feminista cuestionan esos estereotipos desde un horizonte ciertamente transgresor y reivindicativo. Su objetivo era impulsar una toma de conciencia en torno a la desigualdad y la opresión de que eran objeto las mujeres por parte del mainstream. Este tipo de activismo exigió un gran esfuerzo para hacerse un hueco en un mercado que rápidamente comenzaría a saturarse, tras la irrupción del nuevo cómic adulto caracterizado, como hemos visto en el epígrafe anterior, bien por su carácter satírico y reivindicativo, bien por un contenido erótico, en ocasiones exacerbado y mezclado con elementos fantásticos. En ambos casos, la presencia de mujeres en el boom del cómic para adultos deja de estar definida por la representación de lo personal o cotidiano.

Nuria Pompeia es uno de los principales referentes del cómic feminista en España. Desde una posición crítica y en clave de humor, utiliza "la ironía desesperada" y el sarcasmo para retratar la condición femenina. Pompeia colaboró con algunas de las revistas más importantes del momento, como Cuadernos para el Diálogo, Por Favor o Vindicación Feminista, entre otras muchas. Desde 1970 Triunfo publicó semanalmente La educación de Palmira, una de sus tiras más conocidas. En ella criticaba la educación como mecanismo de socialización y de transmisión de unos valores que dirigían a las mujeres directamente hacia el matrimonio y la "infelicidad". La protagonista, al igual que la propia autora, optaban en ese contexto por la rebelión frente a la sumisión y la resignación, en un discurso subversivo dirigido contra el modelo femenino tradicional que constreñía el desarrollo de las mujeres jóvenes. En Mujercitas (1975) Pompeia criticó la institución familiar, al presentar el hogar y la maternidad como elementos de alienación para las mujeres. Apelaba especialmente a toda una generación de progresistas que se manifestaban por la libertad de expresión y de reunión sin cuestionar la situación de discriminación femenina, cuyo verdadero origen resi- 
día en el hogar y en el desigual reparto de tareas que limitaba su militancia política. Paradójicamente, las mujeres eran objeto de una mayor exposición pública, aunque desprovista de cualquier noción reivindicativa al ser consideradas por los medios como objeto de consumo y potenciales consumidoras desde el hogar.

El activismo de Pompeia como precursora del cómic feminista resulta imprescindible para entender el contexto en el que comienzan a cuestionarse las tradicionales representaciones culturales de la maternidad. En uno de sus primeros trabajos, Maternasis (1967), la aborda desde un enfoque ciertamente transgresor al exponer una visión desmitificada del embarazo y del parto que contrastaba con la imagen difundida y aceptada socialmente. En un tono pesimista, acentuado por un trazo esquemático sobre un fondo plano, representa las repercusiones vitales de la maternidad: desde los cambios físicos que experimentan las mujeres con un embarazo que limita y condiciona su actividad, hasta las implicaciones emocionales que derivan en una sensación de inseguridad en torno a sus capacidades como individuo. Maternasis no solo cuestiona la imagen idealizada del embarazo como "dulce espera", sino también la propia naturaleza de las relaciones materno-filiales. En sus viñetas representa la sensación de extrañeza frente a la vida que se está gestando y la posible hostilidad o rechazo que puede experimentar la madre. La imagen de un bebé con una cabeza desproporcionada que yace junto a su progenitora convaleciente tras el parto, que se agita amenazante por su llanto incesante, resulta contundente.

La cuestión de la maternidad y su desmitificación también fue tratada por Montse Clavé (Cádiz, 1946). Ella comenzó dibujando para la revista femenina Sissi (de editorial Bruguera), dirigida a adolescentes, con historietas románticas y sentimentales. Durante la transición su trabajo experimentó un viraje radical al incorporarse al equipo de la revista satírica Butifarra! (Barcelona, 1975) y a la editorial LaSal, voz del feminismo catalán. De este periodo destaca su historieta La mar, publicada en el especial mujeres del cómic adulto Tótem (1979). En esa historieta, Clavé y Mari Chordà nos presentan, a través de la estética underground, una imagen absolutamente desmitificada de la maternidad, ligada a la opresión en el interior del hogar, origen de la soledad y el aislamiento del ama de casa. La principal novedad es la inclusión de elementos eróticos que en cierta forma dificultan la interpretación del discurso. La protagonista de la historieta, que acaba de conocer su embarazo, se masturba frente al mar mientras es acunada por las olas.
Para representar el momento del parto, las autoras recurren a elementos fantásticos: "cuando el sexo se abrió, entre borbotones de agua y algas, salió la barquilla violeta. La mujer se embarcó y adentro, adentro se fue haciendo grande mientras se iba perdiendo" (Chordà, 1977). Una metáfora sobre la pérdida de la identidad y del yo, que se inicia tras el parto.

En los años 80, la maternidad continúa siendo objeto de atención y debate, a pesar de los avances en materia de derechos (despenalización de los anticonceptivos en 1978, apertura de los primeros centros de planificación y orientación familiar, legalización del divorcio en 1981 y despenalización del aborto en 1985, entre otros). La escritora Victoria Sau (Barcelona, 1930) cuestiona el mito de la maternidad desde una perspectiva feminista. Al igual que Clavé, Victoria Sau comenzó escribiendo guiones para cómic femenino, cuentos, libros de cocina y novela rosa, bajo el seudónimo de Vicky Lorca. En este sentido, ambos casos resultan paradigmáticos por su propia evolución derivada de la interiorización y posterior toma de conciencia respecto a unos estereotipos y a un discurso de la desigualdad inherente a las propias estructuras de poder (Jiménez Morales, 2011). En su obra Diccionario ideológico feminista (1981) Sau abordaba la cuestión de la maternidad desde una perspectiva transgresora, poniendo el acento en la familia, "creación masculina y patriarcal" y unidad económica donde tenía lugar la explotación del ama de casa. También trata la naturaleza de la relación materno-filial, en concreto el análisis del vínculo madre-hija, que califica como "la más dramática de todas las relaciones humanas", que pone de relieve la condición servil de la mujer-madre "por toda la herencia relacional, la opresión, discriminación y explotación que ella misma sufre" (Sau, 1981, p. 146). Aunque la socialización y la crianza del hijo varón también se inscribe en el orden patriarcal, a medida que la socialización avanza los lazos madre-hijo se debilitaban en un proceso de progresiva desvalorización de la madre como mujer, de la que además se espera "amor incondicional, abnegación y sacrificio" (Sau, 1981, p. 150). Para Sau, la maternidad, lejos de dotar de un estatus superior a las mujeres como en las sociedades primitivas, era un medio de perpetuar su opresión y un proceso "desvalorizado y jerarquizado" por el patriarcado que lo ha convertido en servidumbre-esclavitud. La madre se convierte en una especie de "porteadora" de los valores del padre, que son al fin y al cabo los valores de la sociedad patriarcal; en realidad actúa como "un padre femenino" (Sau, 1991, p. 181). El patriarcado la ha fagocitado en una especie de matricidio primitivo: 
El poder de vida y muerte, ostentado simbólicamente por la Madre, pasó a manos del Padre, el cual lo ejerció sin reparos y arbitrariamente desde entonces. Desde el control de nacimientos hasta el infanticidio programado, la pena de muerte y la guerra, nadie ha vuelto a escapar del absolutismo paterno (Sau, 1995, p. 15).

Al carecer de trascendencia económica, política o social, la maternidad ha desaparecido como tal, no es más que un "vacío de poder". En su lugar se ha impuesto "una paternidad absolutista, teocrática, monárquica, caudillista, androcéntrica" (Sau, 1995, p. 22). En la misma línea que Badinter (1981), Sau considera que el amor maternal se había desvalorizado al considerarse como instintivo (Sau, 1994).

Las revistas familiares son el contrapunto del cómic y en este sentido constituyen un perfecto ejemplo de transgresión banal. En su momento supusieron toda una novedad en una España supuestamente reconstruida desde fundamentos democráticos e igualitarios, que abogaba por el cambio de los roles tradicionales de género. Sin embargo, al igual que las revistas femeninas de la época, las familiares ensalzaban un falso ideal femenino de modernidad, liberación, autonomía y capacidad para compatibilizar trabajo y vida familiar. La superwoman desplaza al ama de casa, considerada un referente superado. Desde sus redacciones se proyecta un modelo de maternidad y paternidad consciente, basado en el derecho al control de los nacimientos y en nuevos modelos de crianza y educación compartida. Sin embargo, lo hacen utilizando la ambigüedad y la "contención", especialmente evidentes en temas específicamente sexuales, envueltos en un ropaje científico, con una ausencia total de cualquier referencia política o reivindicativa, como veremos en la revista Ser Padres.

La versión española de Eltern (G+J) comenzó su andadura en 1975. Existe pues un desfase con respecto a su homónima alemana, que había comenzado a publicarse en 1966. Los primeros reportajes publicados en Ser Padres eran traducciones casi literales de los contenidos de Eltern. Durante esos años, tanto el comité de redacción como los asesores médicos (pediatras, ginecólogos y demás especialistas) eran varones de origen alemán, a excepción de la dirección a cargo en la edición española del doctor Manuel Rosado. Sus contenidos continúan en cierta forma la tradición decimonónica al legitimar de manera absoluta los discursos científicos de expertos que se pronuncian en torno a la crianza (Jiménez Zunino y Roquero García, 2016, p. 329). En España, como había ocurrido antes en Alemania, Ser Padres introdujo ideas renovadoras en temas como la crianza, la sexualidad y el tradicional rol paterno. El análisis de la revista nos permite establecer dos fases diferenciadas respecto a contenidos y destinatarios: entre 1975 y 1985, y desde 1986 hasta la actualidad. Mientras que la primera etapa podría calificarse como transgresora en muchos aspectos, en la segunda observamos un proceso de estancamiento, cuando no de regresión, acentuado en la década de los 90. En el primer periodo destacan, por ejemplo, los reportajes relativos a la sexualidad dentro del matrimonio, publicados en forma de coleccionables, que incluían todo tipo de diagnósticos y consejos destinados a mejorar la vida sexual de la pareja. De igual forma, se hacían alusiones a la conveniencia del uso de métodos anticonceptivos -incluso a la polémica esterilización masculina o vasectomía- en la línea de lo dispuesto por la Organización Mundial de la Salud. El discurso científico permitía exponer cuestiones relativas al sexo que suscitaron controversia en una sociedad para la que estos temas continuaban siendo tabú. Así, la portada del primer número, en la que aparecían dos niños desnudos para reivindicar la educación sexual dirigida a la infancia y adolescencia fue tildada de pornográfica. Manuel Rosado argumentaba en su defensa que los responsables eran "profesores de Universidad y prestigiosos doctores de la Medicina mundial" (Ser Padres, 5, mayo 1975).

Sin embargo, bajo esa apariencia transgresora en torno a una liberación sexual contenida o más bien constreñida, subyacía la defensa del matrimonio y la familia como institución en riesgo, amenazada por una creciente opinión favorable a la aprobación del divorcio. Pese a todo, Ser Padres llegó a publicar informes como el del doctor Masters o consejos para reavivar la pasión en la pareja, a través de juegos amorosos, aunque en escasas ocasiones se aludía a la impotencia masculina como principal causa de los problemas matrimoniales. Es más, el diagnóstico de los médicos y asesores de la revista señalaba en gran medida a las mujeres como responsables, bien por haber perdido su atractivo físico, bien por mantener una actitud pasiva, cuando no de abierta frialdad hacia las relaciones sexuales. Esa conducta -aseguraban- provenía tanto de la educación recibida, que impedía a la mujer disfrutar del sexo por mojigatería o por pudor, como de las consecuencias de la vida moderna y del cansancio derivado de la (doble) jornada laboral. Aun así, la sexualidad -incluso la reivindicación del orgasmo femenino- no estuvo ni de lejos planteada como vehículo para la liberación o emancipación femenina, sino que se consideraba una solución a las crisis ma- 
trimoniales. En definitiva, representaba una forma de entender la sexualidad muy tradicional al consolidar el papel de sumisión y sacrificio de las mujeres que debían "aprender a conocer los deseos y reacciones de su marido" (véase "El día más feliz y luego la noche, la verdad sobre la noche de bodas". Ser Padres, 6, junio 1975, p. 59) e incluso, convertirse en sus amantes por el bien de la familia y su estabilidad. Este tipo de contenidos, por otro lado, refleja el interés que surge en la sociedad española en lo que respecta al sexo y la sexología matrimonial (García-Fernández, 2017), lo cual se inscribe en un contexto de acelerado cambio social y aperturismo limitado, no obstante, si se analiza desde una perspectiva de género.

Otra de las aportaciones de Ser Padres fue la introducción de un nuevo modelo de paternidad en las antípodas del tradicional autoritarismo con el que se pretendía romper: “¿se siente quizá oprimido en su trabajo y lo compensa jugando al 'hombre fuerte' en su casa? O tal vez tiene algunos temores ocultos que trata de acallar con sus gritos de sargento" (véase "Cuando los padres no están de acuerdo en la educación de sus hijos" Ser Padres, 11, octubre 1975, pp. 57-62). Desde sus inicios, la revista lo cuestiona y propone la imagen del "padre moderno", consciente y presente, incluso en el parto, implicado en la crianza, educación y socialización de sus hijos. En varios artículos se insistía en los riesgos de una educación severa y en la importancia de trasmitir un rol positivo a la infancia. Por otro lado, una actitud autoritaria, agresiva o despreciativa del padre hacia la madre podría desencadenar "tendencias homosexuales" en el hijo varón. El abandono del rol paterno tradicional también tenía por objeto la normalización sexual, en un contexto en el que la homosexualidad continuaba considerándose una desviación. Los psicólogos de la revista la vinculaban a una ausencia de referentes paternos o a una figura paterna distante, circunstancia que provocaba en el niño la necesidad de buscar refugio en el modelo femenino.

En la etapa correspondiente a los años ochenta, los temas relativos a la sexualidad en el matrimonio desaparecen paulatinamente. No obstante, continúa representándose un modelo de crianza compartida donde el papel del padre resulta fundamental, junto a los familiares que forman parte de la red de ayuda y apoyo en un tipo de crianza socializada. Se trata de una "revolución silenciosa", relacionada con la implicación de los padres ya que "lo que antaño fuese motivo de debilidad o vergüenza, se muestra ahora con orgullo. El estrechar contactos con el hijo es otra de- mostración de capacidad y eficacia viril” ("Revolución silenciosa: los nuevos padres". Ser Padres, 135, marzo 1986, pp. 12-17). No obstante, a partir de 1986, se aprecia un cambio de rumbo con la progresiva introducción de contenidos dirigidos exclusivamente a las madres, como principales cuidadoras. Se abordan temas de alimentación, y en concreto la conveniencia de la lactancia materna a la que comienza a dedicarse un importante espacio frente a la lactancia artificial, tan arraigada en España como en otros países de Europa.

La introducción del debate sobre la conveniencia de renunciar al trabajo extradoméstico para centrarse en la crianza coincide con un estancamiento del feminismo y de sus principales objetivos, algunos de los cuales, como la despenalización de los anticonceptivos, el aborto y el divorcio, ya se habían institucionalizado. La aparición de esta controversia en una revista dirigida a mujeres jóvenes con hijos y un perfil profesional por encima de la media, nos advierte de los primeros signos de agotamiento del modelo de superwoman, que comienza a ser cuestionado (véanse "Mujeres que hacen un alto en el camino para ser madres". Ser Padres, 124, marzo 1985, pp. 15-17; "Madre contra madre. ¿Cuál es la mejor, la que trabaja o la que se queda en casa?" Ser Padres, 32, noviembre 1985, pp. 14-17; "Supermamás. Trabajar y tener hijos, ¿una ecuación imposible?" Ser Padres, 206, enero 1992, pp. 20-26; "De profesión, imis hijos! Cuando quedarse en casa es una decisión (Testimonios de madres)". Ser Padres, 14, septiembre 1992, pp. 24-26). Ser Padres renunciaba así al destinatario masculino, definiéndose como una revista femenina dirigida a la mujer con hijos. Por aquel entonces, el $40 \%$ de los contenidos respondía a temas especializados relacionados con la maternidad, el embarazo, el parto, la crianza y la educación de los hijos, mientras que el $60 \%$ restante se dedicaba a temas de "interés femenino": belleza y moda, hogar, cocina y labores, reportajes, cultura, sexualidad etc. (véase "Ser Padres y sus lectoras". Ser Padres, especial, noviembre 1985).

La distribución de estos contenidos obedece a la necesidad de posicionarse en un mercado editorial sujeto a importantes cambios tras la llegada de grupos de prensa extranjeros (Gallego Ayala, 1990, pp. 71-83). La competencia es feroz tras la eclosión de revistas femeninas como Vogue, Elle o Marie Claire, dirigidas a mujeres con intereses aparentemente más superficiales como la moda o la belleza. Además, a partir de 1988 apareció una competidora directa con el título Crecer Feliz (Hachette). En esta y otras revistas femeninas dirigidas a mujeres con hijos, el 
interlocutor masculino desparece por completo ante la figura de la madre como principal proveedora de cuidados. Mi bebé y yo, publicada en 1992, certifica el cambio de tendencia al recuperar la maternidad como elemento central de la identidad femenina. Los discursos de expertos presentan la crianza intensiva o con apego como modelo de referencia (Hays, 1998). Actualmente las revistas de este campo asumen plenamente la sumisión de los progenitores a las demandas del bebé. Lo hacen ensalzando la figura de la mujer-madre como valedora de unos cuidados que requieren dedicación absoluta, incluso desde el ámbito emocional y cognitivo. Al mismo tiempo invisibilizan progresivamente la figura paterna, representada por sujetos no competentes necesitados de tutela, consejo y asesoramiento en estos temas (Medina Bravo, Figueras Maz y Gómez Puertas, 2014).

Aunque la crianza con apego aparece como un nuevo modelo, sus orígenes se remontan a los 90, en un contexto de crisis económica que favoreció la emergencia de narrativas sobre la maternidad envueltas en un discurso aparentemente transgresor, fundamentado en una supuesta vuelta a "lo natural", que en realidad revitalizaba los viejos discursos de la diferencia. Este "nuevo" referente, constata el fracaso, la superación o el agotamiento de la figura de la superwoman, incapaz de resolver las contradicciones inherentes a su propia construcción. Se trata de un proceso que evidencia cómo en las coyunturas de crisis económica e identitaria las mujeres son "devueltas" al hogar, con la ayuda de los discursos de expertos que llegan a utilizar la retórica feminista para avalar unos objetivos involucionistas. La ofensiva naturalista, lejos de ser transgresora o innovadora, no es más que una regresión que trata de devolver la maternidad al centro del destino femenino (Badinter, 2011).

\section{CONCLUSIONES}

Con unas fuentes tan diversas nuestro objeto de estudio no podría constituir más que una mera aproximación a la construcción de los ideales transgresores, en unos años cruciales que nos permiten explicar tanto la evolución de los modelos de género, como algunas de sus reminiscencias visibles en la actualidad. La transgresión, que hemos denominado banal, no fue en absoluto trivial o de escasa transcendencia. El franquismo condicionó a una generación que, fuera del compromiso político, no disponía de una reserva teórica o de unas herramientas ideológicas sólidas que permitieran canalizar las actitudes transgresoras más allá de la transformación aparente. Así que la disparidad de objetivos y de manifestaciones actuaba como rasgo definidor de una nueva identidad suspendida, inestable, efímera, pero consciente, que además enlazaba con la dinámica reivindicativa, transgresora, y en ocasiones, con las tendencias anómicas que empezaban a materializarse en la sociedad occidental de los 80. El valor del cambio es en este sentido performativo porque las imágenes o las palabras no tenían por objeto describir una realidad sino construirla. El discurso transgresor de esos años, en sus múltiples manifestaciones muestra una transformación total de los roles de género. Se utiliza un lenguaje que en apariencia ya no subordina ni excluye a las mujeres, sino que incluso se muestra integrador apelando a una libertad sexual absoluta. Pero en realidad se trata de una transgresión que no reformula las categorías de género (Butler, 2007 , pp. 84-87). Aunque sus efectos sociales o ideológicos puedan parecer irrelevantes, abrió un orificio de respiración a un proceso de cambio que en principio no buscaba perpetuarse sino sorprender al sistema y desproveerlo de catalogaciones. Evidentemente no existía un imaginario transgresor unívoco o una única identidad subversiva, de modo que el análisis de su impacto sobre los estereotipos de género se convierte en un objeto de estudio complejo.

Desde la transgresión que representan los discursos libertarios hasta aquella que proyectan las revistas familiares, con la evolución-involución del modelo de mujer, observamos una progresiva toma de conciencia en torno a la necesidad de cambiar los roles tradicionales, fundamentados en actitudes esencialistas. Pero de forma paralela, las narrativas de género desarrolladas desde el poder se reinven$\tan$ y utilizan estrategias discursivas sumamente efectivas, apropiándose de una retórica feminista o construyendo "nuevas" versiones del feminismo para encubrir una mirada conservadora e incluso reaccionaria en torno al papel que deberían representar las mujeres en la sociedad.

\section{AGRADECIMIENTOS}

Este trabajo se ha realizado en el marco del proyecto Género, compromiso y transgresión en España, 1890-2016 (FEM2016-76675-P), financiado por el Ministerio de Economía y Competitividad. 


\section{NOTAS}

[1] En la misma línea se expresa Michelle Brigandage "de 55 años, quien dirige la marca de ropa sexy hooligans y canta en la banda brigandaje: no puedo explicar lo poderoso que era caminar por la calle donde los hombres te juzgaban diariamente por tu apariencia y verlos estremecerse iy retroceder con horror!" (véase Cole, 2015, 3 de junio).

[2] En un artículo publicado en El País titulado "Mayo del 68 mata a su padre", se informa sobre El gran bazar, una obra de 1975 en la que el "político verde" narra su experiencia como monitor en una escuela infantil de Fráncfort, escrita "con la meta poco disimulada de provo- car a la conservadora sociedad germana en una época donde florecían las proclamas antisistema y los jóvenes exigían poner fin a todos los tabúes sexuales" (Müller, 2013, 10 de mayo).

[3] La periodista, Karmele Marchante, no disimula su animadversión ante el entrevistado de quien dice que cuando sonríe "muestra unos dientes de una antiestética que solo tiene parangón con la prominente barriga que luce y muestra con orgullo".

[4] Marchante formaba parte de LAMAR (Liga Antipatriarcal de Mujeres Antiau- toritarias y Revolucionarias), surgida en 1975 de la escisión del Colectivo Feminista de Barcelona, que se convertirá en el Partido Feminista (Gil, 2010, p. 145). En una entrevista concedida a la revista Smoda, señala que en aquella época se dedicaban a "a quemar Interviús en la plaza Cataluña vestidas de negro y gritando contra Jomeini lemas como Jomeini, cabrito, ponte tú el benito". Eso, cuando no estaba viajando a congresos internacionales, defendiendo la libertad homosexual de las mujeres u organizando jornadas de autogestión "para conocer nuestro propio cuerpo con espéculos" (Ramírez, 2014, 28 de mayo).

\section{BIBLIOGRAFÍA}

Acedo, R. y Barbarà, C. (2010). Mary Noticias. Amor, misterio, aventura. Reedición de los 15 primeros números de 1960. Barcelona: Aleu.

Alberdi, I. (1996). Nuevos roles femeninos y cambio familiar. En: García de León, M. A., García de Cortázar, M. y Ortega, F. (coords.). Sociología de las mujeres españolas. Madrid: Editorial Complutense, pp. 41-69.

Austin, J. L. (1991). Como hacer cosas con las palabras. Palabras y acciones, Barcelona: Paidós.

Badinter, E. (1981). ¿Existe el amor maternal?: Historia del amor maternal, siglos XVII al XX. Barcelona: Paidós.

Badinter, E. (2011). La mujer y la madre. Un libro polémico sobre la maternidad como nueva forma de esclavitud. Madrid: La esfera de los libros.

Baudrillard, J. (1984). Cultura y simulacro. Barcelona: Kairós.

Beltrán, M. (1987). La pirámide de cristal. Una aventura de Cleopatra. Barcelona: Complot.

Benavides, F. (2016). El cuerpo como espacialidad ambigua: Somato-política y resistencias corporales en Michel Foucault. Daimon. Revista Internacional de Filosofía, Suplemento 5, pp. 601-610. https://doi.org/10.6018/daimon/268671

Bourdieu, P. (1988). La Distinción. Criterios y bases sociales del buen gusto. Madrid: Taurus.
Butler, J. (2007). El género en disputa. El feminismo y la subversión de la identidad, Barcelona: Paidós

Chordà, M. (1977). La mar. Tótem, extra 2. Especial mujeres, pp. 95-97.

Dardigna, A. M. (1978). La presse "féminine". Fonction idéologique, Paris: François Maspero.

Domínguez Juan, M. M. (1988). Representación de la mujer en las revistas femeninas, Madrid: Universidad Complutense de Madrid.

Fitoussi, M. (1989). Hasta el moño (de ser superwoman). Barcelona: Muchnick.

Gallego Ayala, J. (1990). Mujeres de papel: de iHola! a Vogue: la prensa femenina en la actualidad. Barcelona: Icaria.

García Fernández, M. (2017). Sexualidad y armonía conyugal en la España franquista. Representaciones de género en manuales sexuales y conyugales publicados entre 1946 y 1968. Ayer. Revista de Historia Contemporánea, 105 (1), pp. 215-238.

Garrido, L. (1992). Las dos biografías de la mujer en España. Madrid, Instituto de la Mujer. Ministerio de Asuntos Sociales.

Gil, S. (2010). Nuevos feminismos. Sentidos comunes en la dispersión. Madrid: Traficantes de Sueños.

Gómez Alonso, R. (2013). La estética de la rebeldía: del situacionismo a la okupación. Arte y Ciudad - Revista de Investigación, 3 (1), pp. 199-214.
Hays, S. (1998). Las contradicciones culturales de la maternidad. Barcelona: Paidós.

Hernández Velasco, I. (2017, 7 de mayo). Daniel Cohn-Bendit: "Tenemos que reinventar la democracia con fantasía". El Mundo [En línea]. Disponible en: http:// www.elmundo.es/cronica/2017/05/07/ 590dd1d3268e3ed73a8b457e.html

Jareño, C. (2016). Una democracia sexual. Destape, liberación sexual y feminismo: ¿una combinación imposible? En: Naval López, M. A. y Carandell, Z. (coords.). La transición sentimental: literatura y cultura en España desde los años 70. Madrid: Visor Libros, pp. 179-198.

Jiménez Morales, R. (2011). Pequeños defectos que debemos corregir: aprendiendo a ser mujer en la historieta sentimental de los años cincuenta y sesenta. Arbor, 187 (Extra 2), pp. 159-168. https://doi. org/10.3989/arbor.2011.2extran2116

Jiménez Zunino, C. y Roquero García, E. (2016). Los discursos expertos sobre la crianza y maternidad: aproximación al caso español 1950-2010. Arenal, 23 (2), pp. 321-345.

Lladó, F. (2001). Los cómics de la transición. El boom del cómic adulto (1975-1984). Barcelona: Glénat.

Medina Bravo, P., Figueras Maz. M. y Gómez Puertas, L. (2014). El ideal de madre en el siglo XXI. La representación de la maternidad en las revistas de familia. Estudios sobre el mensaje periodístico, 20 (1), pp. 487-504. https://doi.org/10.5209/rev_ ESMP.2014.v20.n1.45244 
Melville, K. (1980). Las comunas en la contracultura. Origen, teorías y estilos de vida. Barcelona: Kairós.

Miguel, A. de (2015). Neoliberalismo sexual. El mito de la libre elección, Madrid: Cátedra.

Mira Abad, A. y Moreno Seco, M. (2004). Maternidad y evolución de la identidad femenina en la España del siglo XX. En: Val Valdivieso M. I. del, Santo Tomás, M., Dueñas, M. J. y Rosa, C. de la (coords.). La historia de las mujeres: una revisión historiográfica. Valladolid: Universidad de Valladolid, pp. 315-334.

Müller, E. (2013, 10 de mayo). Mayo del 68 mata a su padre. El País. [En línea]. Disponible en: https://elpais.com/elpais/2013/05/10/gente/1368181442_347734.html

Muñoz Ruíz, M. C. (2002). Mujer mítica, mujeres reales: las revistas femeninas en España, 1955-1970. [Tesis doctoral inédita]. Madrid: Universidad Complutense de Madrid.

Nelly, R. (1989). Masculino/Femenino. Prácticas de la diferencia y cultura democrática. Santiago de Chile: Francisco Zegers Editor.

Pardo, J. L. (2006). La Banalidad. Barcelona: Anagrama.

Pons, A. (1984). María Lanuit. Nocturno. Solo y otras historias. Barcelona: La Cúpula.

Pons, A., Guerrero, M. y Galiano, J. L. (1985). Las Internas. Barcelona: La Cúpula.

Ramírez, N. (2014, 28 de mayo). Ellas también escribieron la contracultura en 'Ajoblanco'. Feministas, escritoras y mujeres clave de los 70 y los 90 hicieron historia en la mítica revista alternativa española. El País. [En línea]. Disponible en: https://smoda.elpais.com/moda/ ellas-tambien-escribieron-la-contracultura-en-ajoblanco/

Ribas, P. (1980). De qué van las comunas, Barcelona: La Piqueta.

Ribas, P. (2011). Los '70 a destajo. Ajoblanco y la libertad, Barcelona: Destino.

Ribas, P., Puig, T. y Esteban, J. (coords.) (2004). Ajoblanco, las ideas que incendiaron los setenta. Barcelona: Ajoblanco Editorial Multimedia.

Romero, P. (2017). Nunca fuimos "superwoman": redefiniendo la identidad femenina. En: Suárez-Villegas, J. C., Guadarrama Rico, L. A., Valero Vilchis, J. y Panarese, P. (eds.). La desigualdad de género invisibilizada en la comunicación. Madrid: Dykinson, pp. 1-15.

Romo Parra, C. (2001). Tiempos de trabajos: los límites difusos de las horas excedentes para las mujeres en España (1964-1975). Arenal, 8, pp. 55-81.

Sau, V. (1981). Diccionario ideológico-feminista. Barcelona: Icaria.

Sau, V. (1991). La ética de la maternidad. En: Luna. L. G. (comp.) Mujeres y Sociedad. Nuevos enfoques teóricos y metodológicos. Barcelona: Seminario Interdisciplinar Mujeres Sociedad, pp. 177-182.

Sau, V. (1994). La maternidad, una impostura. Duoda, Revista d'Estudis Feministes, 6, pp. 97-113.

Sau, V. (1995). El vacío de la maternidad. Madre no hay más que ninguna. Barcelona: Icaria.

Shipman, C. y Kay, K. (2009). Womenomics. Write your own rules for success. New York: Harper Collins.

Wolen, P. (2006). El asalto a la nevera. Reflexiones sobre la cultura del siglo XX. Madrid: Akal.

\section{Recursos en línea}

Ana Curra: "Hubo dos Movidas: la light que se ha vendido, y la de los perdedores y transgresores". Jot Down, febrero 2014. [En línea]. Disponible en: http://www. jotdown.es/2014/02/ana-curra-hubodos-movidas-la-light-que-se-ha-vendidoy-la-de-los-perdedores-y-transgresores/

Cloaca. Ajoblanco, 18, enero 1977, pp. 48-51. [En línea]. Disponible en https://drive. google.com/file/d/1E2oTW9Kj6UIT9ZYDOwRd_6QZ44cgN7g/view

Cloaca. Ajoblanco, 25, septiembre 1977, pp. 62-65. [En línea]. Disponible en https://drive.google.com/file/d/1B2TUZkFZLfypIX_ pBp5OSbqFfHvGY6Bi/view

Cole, B. (2015, 3 de junio). Si el punk nunca muere, entonces, ¿cómo envejece? $i-d$ Vice. [En línea]. Disponible en: https://id.vice.com/es mx/article/neb3m7/ si-el-punk-nunca-muere-entonces-cmoenvejece

Cuadernos comuneros. Ajoblanco, 24, julio 1977, pp. 90-97.

Entrevista a Mique Beltrán. El Portaluco, 12 de noviembre 2015. [En línea]. Disponible en: https://elportaluco.com/ entrevista-a-mique-beltran/

Marchante, K. Sostenes y violetas a Teresa Pàmies, de las radicales con amor. Ajoblanco, 20, marzo 1977, p. 40. [En línea]. Disponible en: https://drive.google.com/file/d/1jzbnegOA_2vnpTb49kL pr8qqdZplaA1V/view

Savater, F. Sobre la contracultura, la incultura y todo lo que lleva a la sepultura. Ajoblanco,18, enero 1977, p. 22. [En línea]. Disponible en https://drive.google.com/file/d/1E2oTW9Kj6UIT9ZYDOwRd 6QZ44cgN7g/view 